\title{
CRYPTOSPORIDIUM PARVUM IN CLINICALLY EXAMINED DAIRY CALVES; MOLECULAR AND BIOCHEMICAL STUDIES
}

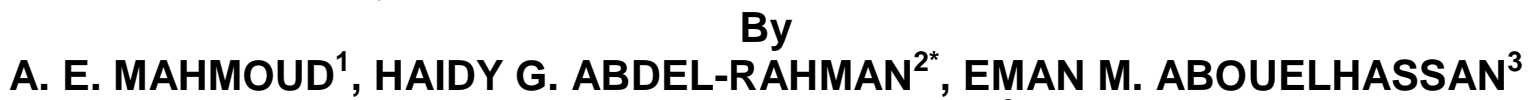 AND NAHLA H. SALLAM ${ }^{3}$}

Departments of Animal Medicine ${ }^{1}$, Clinical Pathology ${ }^{2}$ and Parasitology ${ }^{3}$, Faculty of Veterinary Medicine, Suez Canal University, Ismailia 41522, Egypt ( ${ }^{*}$ Correspondence: Email: haidy.galal@vet.suez.edu.eg)

\section{Abstract}

Cryptosridiosis is a life threatening illness of neonatal calves, leading to mal-absorption and diarrhea. The present study was carried out on 25 Holstein dairy calves, 3 to 15 days old in ElEman farm, Ismailia Governorate, Egypt. Animals were assigned into two groups; G1: included 20 calves suffered from watery to mucoid diarrhea and G2: included 5 calves were proved to be clinically healthy and used as a control one. The diseased calves were treated by oral administration of Halofuginone at a dose rate of $100 \mu \mathrm{g}$ per $\mathrm{kg}$ once daily for 7 successive days. A total number of 90 blood and fecal samples were obtained from all animals during the study; 40 blood samples from diseased calf (at the onset of the appearance of the symptoms and on the $8^{\text {th }}$ day of the treatment), 40 fecal samples at the same pattern from the same animals and 10 samples (blood and feces) were collected from the control one. Forty-five blood samples were analyzed for serum enzyme activities of ALT, GGT and LDH and for serum levels of urea, creatinine, total protein, albumin, globulin, IgA, TC, TGs, HDL-C and LDL-C. The later, forty-five fecal samples were examined to detect Cryptosporidium infection utilizing ICT, microscopical and molecular identification based on $18 S$ rRNA Gene. Clinically infected dairy calves showed clinical signs of profuse watery diarrhea with yellowish colored feces $(40 \%)$ and other calves showed mucoid diarrhea $(60 \%)$ which persist for 7 days resulting in dehydration, weakness and loss of body weight. The study revealed a significant increase in levels of ALT, GGT, LDH and urea with a highly significant reduction in concentration of $\operatorname{IgA}$ in the diseased calves. Meanwhile, a non-significant change in levels of total protein, albumin and globulin were reported among all groups. Lipid profile of the diseased calves revealed a significant increase in both levels of T.C and LDL-C with a highly significant reduction in the level of T.Gs in the diseased calves. Meanwhile, HDL-C level showed a non-significant change in all groups.

Keywords: Cryptosporidium, Calves, diarrhea, hepatic, renal, IgA, Halofuginone, PCR

\section{Introduction}

Cryptosporidiosis is becoming one of the important zoonotic diseases causing a respiratory and gastrointestinal illness which caused by an apicomplexan protozoan parasite called Cryptosporidium (Yagita et al, 2001). It is considered a life threatening illness of neonatal calves leading to malabsorption and diarrhea, which in turn result in economic losses in animal husbandry (Azami, 2007). C. parvum an obligate intracellular parasite commonly affect newborn calves 5 to 15 days old showed varying degrees of apathy, reduced feed intake associated with a signs of diarrhea, which persists for several days, feces are yellow or pale, watery and can contain mucus. Persistent diarrhea can result in dehydration, a marked loss of body weight and emaciation (Radostits et al, 2007). Diarrhea can cause dehydration, metabolic acidosis and impaired function of many organs, manifested by several metabolic disturbances expressed by biochemical and enzymatic alterations (Ghanem et al, 2012). Abdel Megeed, et al. (2015) mentioned that cryptosporidium infected calves showed yellowish, greenish or clay colored profuse watery diarrhea, anorexia, colic pain, normal body temperature, reduced milk suckling and with progression of the disease, animals dehydrated with evidence of lying down posture.

Diagnosis of cryptosporidiosis usually depends on the morphological identification which needs time, effort and experience, as well as, is insufficient to confirm infection. 
Consequently, the use of molecular techniques for Cryptosporidium identification was more common to solve a lot of problems accompanied with morphological identification (Ghoneim et al, 2017). Although PCR is as a very sensitive method to detect Cryptosporidium, yet it is too expensive for routine diagnosis (Bialek et al, 2002).

Various treatment trials were tried to test the efficiency of some agents as bovine hyper immune colostrum, halofuginone and paromycin against cryptosporidiosis (Harp et al, 1996; Lefay et al, 2001).

The study aimed to monitor the changes in clinical signs and biochemical parameters in dairy calves cryptosporidiosis, to compare between the immune chromatographic test (ICT), microscopic and molecular examination to detect cryptosporidiosis and to evaluate effect of Halocur (Halofuginone lactate) in treatment.

\section{Material and Methods}

The present study was carried out on 25 Holstein dairy calves ( 5 male \& 20 female), their ages were ranged from 3 to 15 days old in El-Eman farm, El-Manayf, Ismailia Governorate, Egypt. These animals were assigned into two groups; the first group (G1), include20calves suffered from watery to mucoid diarrhea and the second group (G2) include 5calves were proved to be clinically healthy and used as a control one. Calves during the period of study were kept together under open half shelter system and fed on a milk diet twice daily and tap water was provided ad libitum. Physical examination of diseased and healthy calves was conducted according to the clinical examination procedures (Radostits et al, 2000).

A total number of 90 blood and fecal samples were collected from all animals during the study; 40 blood samples from diseased calf (at the onset of the appearance of the symptoms and on the $8^{\text {th }}$ day of the treatment) and 40 fecal samples at the same pattern from the same animals and 10 samples (blood and feces) were collected from the control one.
Blood was collected from the jugular vein from all calves under the study. The blood was placed in plain tubes, left at room temperature for clot formation, and centrifuged at $3000 \mathrm{rpm}$ for $15 \mathrm{~min}$. The obtained clear sera were collected and stored at $-20^{\circ} \mathrm{C}$ until used for the biochemical analysis (Coles, 1986).

The fecal samples were collected directly from the rectum using examination gloves and stored closed in fecal cups at $4{ }^{\circ} \mathrm{C}$ until being examined.

All analytical biochemical kits were obtained from Biodiagnostic Company (Cairo, Egypt). Meanwhile, Bovine IgA ELISA kit was obtained from MyBioSource, USA. Halocur $^{\circledR}$ drug (each ml contain $0.05 \mathrm{mg}$ Halofuginone lactate) was obtained from MSD, Animal health, New Zeland. For rapid detection of cryptosporidia; Rapid BoviD-5 Ag test Kit supplied by BioNote Company, Korea was used.

Biochemical analysis: Hepatic and renal biomarkers: Serum alanine aminotransferase (ALT) enzyme activity was investigated (Reitman and Frankel, 1957), gamma glutamyl transferase (GGT) (Szasz, 1969) and lactate dehydrogenase (LDH) (Zimmerman and Henery, 1979). Serum level of urea was determined as (Coulombe and Favreau, 1963) and creatinine(Henry, 1974).

Serum proteinogram \& IgA: Total serum protein level was determined (Gornall et al, 1949), albumin level was assessed (Bartholomew and Delaney, 1964). Serum level of globulin was calculated by subtracting the serum albumin from total serum protein (Kaneko et al, 1997). IgA level was determined according to the enclosed pamphlet.

Lipid profile: Total cholesterol (TC) was determined by enzymatic colorimetric method (Allain et al, 1974), triglycerides (TGs) was performed (Fossati and Prencipe, 1982). Serum concentrations of High density lipoprotein cholesterol (HDL-C) (Tiez, 1990) and low density lipoprotein cholesterol (LDL-C) was assessed (Bachorik, 2000). 
Fecal examination: A total of 45 fecal samples were utilized, the first 20 samples before treatment were positive by immune chromatographic test (ICT), and then examined microscopically and kept at $-20^{\circ} \mathrm{C}$ until processed for DNA extraction.

Morphological detection and identification of Cryptosporidium oocysts: 45 fecal samples were examined by concentration floatation technique using sugar (Georgi and Georgi, 1990).Emulsified fecal specimens were dried, fixed in methanol and stained by modified Ziehl-Neelsen technique (Henriksen and Pohlenz, 1981) and examined under oil immersion.

Molecular identification: The first group fecal samples before treatment were utilized, and kept at $-20^{\circ} \mathrm{C}$ until processed for DNA extraction.

DNA Extraction: DNA was extracted from fecal samples using Genomic DNA purification kit (Applied biotechnology) after manufacturer's recommendations. DNA concentration and purification were measured using a Nano Drop, and stored at $-20{ }^{\circ} \mathrm{C}$ until use.

C. parvum molecular identification based on 18S rRNA Gene: C. parvum18S rRNA was amplified from each sample using nested conventional PCR methodologies, the reaction mixtures and primers (Bialek et al, 2002), the outer primer set CPr I (5'- AAA CCC CTT TACAAG TAT CAA TTG GA$\left.3^{\prime}\right)$ \& CPr II (5' - TTC CTATGT CTG GAC CTG GTG AGT T-3') is complementary to a region of the small subunit ribosomal RNA gene of $C$. parvum, amplifying a 676 by sequence. In addition to the inner primer set CPr III (5'- TGC TTA AAGCAG GCA TAT GCC TTG AA-3') \&CPr IV (5'AACCTC CAA TCT CTA GTT GGC ATA GT-3'). PCR was ran following the cycling condition: initial denaturation at $94^{\circ} \mathrm{C}$ for 5 minutes followed by 30 cycles of $94^{\circ} \mathrm{C}$ for $30 \mathrm{~s}, 72^{\circ} \mathrm{C}$ for $1 \mathrm{~min} . \& 72^{\circ} \mathrm{C}$ for $5 \mathrm{~min}$. High melting temperatures of inner primer set allowed a two-step nested PCR with high stringency. Amplification products were separated on $1.6 \%$ agarose gel containing $0.4 \mu \mathrm{g} /$ $\mathrm{ml}$ of ethidium bromide (Bio-Rad Laboratories Inc., Hercules, $\mathrm{CA}$ ) and the gel was run at 90 volts for 40-60 min. and then imaged.

Sequence analysis: PCR products were purified and sent for sequencing, the Sequences were analyzed through BLAST using MEGA7 software.

Phylogenetic analysis: Phylogenetic analysis of samples and the other Cryptosporidium samples of the same genus from the GenBank were performed using UPGMA approaches and the tree was constructed using MEGA7 methods (Fig. 3).

Treatment: Calves were treated by oral administration of Halofuginone at a dose rate of $100 \mu \mathrm{g} / \mathrm{kg}$ once daily for 7 successive days (Radostits et al, 2007).

Statistical analysis: Data were analyzed using independent and paired T-test through SPSS, version, 20 (Levesque, 2007).

\section{Results}

Clinical examination of diseased calves showed profuse watery diarrhea with yellowish colored feces (8/20) $40 \%$ and mucoid diarrhea (12/20) 60\% which persist for 7 days resulting in dehydration, weakness and loss of body weight. Symptoms were highly detected in young calves aging less than one month and decreased with increasing age. Biochemical assessment of serum manifested a significant increment in levels of ALT, GGT, LDH and urea in diseased calves as compared with the control healthy one with a significant decrement in the treated calves when compared with the diseased one. Meanwhile, a non-significant change in creatinine level was reported in all groups (Tab. 1). Also, a non-significant change in levels of total protein, albumin and globulin were reported among all groups. Meanwhile, concentration of IgA revealed a highly significant reduction in the diseased calves as compared with healthy one, with a highly significant rise in the treated calves when compared with the diseased one (Tab. 2). Lipid profile of diseased calves revealed a significant increase in both levels of cholesterol and LDL-C in the diseased calves as 
compared with healthy one without significant difference in treated calves as compared to diseased one. T.Gs level showed a highly significant decrease in the diseased calves as compared with healthy one, without significant difference in treated calves as compared to diseased one, HDL-C level without significant change in all groups (Tab. 3). They showed a complete cure 8 days after starting treatment that continued for seven successive days. Fecal 20/45 samples were ICT positive in diseased calves before treatment, 20 samples were negative in treated and healthy calves. Detection of oocysts showed Table 1: M \pm S.E for serum hepatic \& renal bior treatment.

\begin{tabular}{|l|l|l|l|l|}
\hline Analytes & Groups & \multicolumn{2}{|l|}{ Mean values \pm S.E } & P-value \\
\hline \multirow{2}{*}{ ALT (U/L) } & Control vs D.Pre & $13.67 \pm 0.88$ & $26.7 \pm 1.54$ & $0.001^{* *}$ \\
\cline { 2 - 5 } & D.Pre vs D.Post & $26.7 \pm 1.54$ & $17.62 \pm 1.78$ & $0.014^{* *}$ \\
\hline \multirow{2}{*}{ GGT (U/L) } & Control vs D.Pre & $10.37 \pm 0.53$ & $14.45 \pm 0.58$ & $0.003^{* *}$ \\
\cline { 2 - 5 } & D.Pre vs D.Post & $14.45 \pm 0.58$ & $11.8 \pm 0.41$ & $0.014^{*}$ \\
\hline \multirow{2}{*}{ Creatinine (mg/dL) } & Control vs D.Pre & $1228 \pm 71.5$ & $1345 \pm 77.5$ & $0.014^{*}$ \\
\cline { 2 - 5 } & D.Pre vs D.Post & $1345 \pm 77.5$ & $1112 \pm 93.2$ & $0.015^{*}$ \\
\hline \multirow{2}{*}{ Urea (mg/dL) } & Control vs D.Pre & $1.0 \pm 0.06$ & $0.84 \pm 0.04$ & $0.160^{\mathrm{NS}}$ \\
\cline { 2 - 5 } & D.Pre vs D.Post & $0.84 \pm 0.04$ & $0.85 \pm 0.05$ & $0.844^{\mathrm{NS}}$ \\
\cline { 2 - 5 } & Control vs D.Pre & $20.33 \pm 1.20$ & $25.38 \pm 1.24$ & $0.047^{*}$ \\
\cline { 2 - 5 } & D.Pre vs D.Post & $25.38 \pm 1.24$ & $21.5 \pm 1.46$ & $0.032^{*}$ \\
\hline
\end{tabular}

D.Pre: diseased calves pre-treatment, D.post: diseased calves post-treatment, vs: versus. ${ }^{\text {ns }}$ : nonsignificant $(\mathrm{p}>0.05), *$ : significant $(\mathrm{p} \leq 0.05) . * *$ : highly significant $(\mathrm{p}<0.01)$.

Table 2: $\mathrm{M} \pm \mathrm{S}$.E for serum proteinogram and IgA concentration in cryptosporidiosis calves before and after treatment.

\begin{tabular}{|c|c|c|c|c|}
\hline Analytes & Groups & \multicolumn{2}{|c|}{ Mean values \pm S.E } & P-value \\
\hline \multirow{2}{*}{ Total proteins (gm/dL) } & Control vs D.Pre & $5.9 \pm 0.17$ & $5.68 \pm 0.17$ & $0.508^{\mathrm{NS}}$ \\
\cline { 2 - 5 } & D.Pre vs D.Post & $5.68 \pm 0.17$ & $6.0 \pm 0.15$ & $0.266^{\mathrm{NS}}$ \\
\hline \multirow{2}{*}{ Albumin (gm/dL) } & Control vs D.Pre & $2.93 \pm 0.07$ & $2.53 \pm 0.2$ & $0.260^{\mathrm{NS}}$ \\
\cline { 2 - 5 } & D.Pre vs D.Post & $2.53 \pm 0.2$ & $2.78 \pm 0.17$ & $0.262^{\mathrm{NS}}$ \\
\hline \multirow{2}{*}{ Globulin (gm/dL) } & Control vs D.Pre & $2.96 \pm 0.12$ & $3.16 \pm 0.09$ & $0.308^{\mathrm{NS}}$ \\
\cline { 2 - 5 } & D.Pre vs D.Post & $3.16 \pm 0.09$ & $3.21 \pm 0.11$ & $0.714^{\mathrm{NS}}$ \\
\hline \multirow{2}{*}{$\mathrm{IgA}(\mathrm{mg} / \mathrm{dL})$} & Control vs D.Pre & $294.6 \pm 1.9$ & $277.4 \pm 1.4$ & $0.009^{* *}$ \\
\cline { 2 - 5 } & D.Pre vs D.Post & $277.4 \pm 1.4$ & $350.9 \pm 5.1$ & $0.006^{* *}$ \\
\hline
\end{tabular}

Table 3: $\mathrm{M} \pm \mathrm{S}$.E for serum lipid profile in cryptosporidiosis calves before and after treatment.

\begin{tabular}{|c|c|c|c|c|}
\hline Analytes & Groups & \multicolumn{2}{|c|}{ Mean values \pm S.E } & P-value \\
\hline \multirow{2}{*}{ TC (mg/dL) } & Control vs D.Pre & $91.5 \pm 2.02$ & $131.6 \pm 7.6$ & $0.012^{*}$ \\
\cline { 2 - 5 } & D.Pre vs D.Post & $131.6 \pm 7.6$ & $128.3 \pm 12.6$ & $0.847^{\mathrm{NS}}$ \\
\hline \multirow{2}{*}{ T.Gs (mg/dL) } & Control vs D.Pre & $104 \pm 1.5$ & $78.38 \pm 1.3$ & $0.001^{* *}$ \\
\cline { 2 - 5 } & D.Pre vs D.Post & $78.38 \pm 1.3$ & $74.88 \pm 3.6$ & $0.356^{\mathrm{NS}}$ \\
\hline \multirow{2}{*}{ LDL-C (mg/dL) } & Control vs D.Pre & $27.37 \pm 1.79$ & $50.58 \pm 3.1$ & $0.002^{*}$ \\
\cline { 2 - 5 } & D.Pre vs D.Post & $50.58 \pm 3.1$ & $65.68 \pm 11.3$ & $0.251^{\mathrm{NS}}$ \\
\hline \multirow{2}{*}{ HDL-C (mg/dL) } & Control vs D.Pre & $43.33 \pm 0.33$ & $47.75 \pm 1.5$ & $0.123^{\mathrm{NS}}$ \\
\cline { 2 - 5 } & D.Pre vs D.Post & $47.75 \pm 1.5$ & $43.63 \pm 1.7$ & $0.145^{\mathrm{NS}}$ \\
\hline
\end{tabular}




\section{Discussion}

In this study, symptoms were highly detected in young calves of age less than one month and decreased with age progress. Similar observations were reported by Göz et al. (2006) and Osman and Sadiek (2008). Moreover, Radostits et al. (2007) reported that cryptosporidium infection in calves associated with varying degrees of villus atrophy suggest that digestion and absorption may be impaired, conducting diarrhea.

In the present study, Cryptosporidium was detected firstly with ICT which is a sensitive and rapid method for cryptosporidiosis detection (Vanathy et al, 2017), then with microscopical and molecular examination. The morphological character of detected Cryptosporidium species was similar to $C$. parvum, the diameter of Cryptosporidium oocyst was $3.99 \times 4.6 u m$, similar to those obtained by Fayer et al. (2000), morphological diagnosis of Cryptosporidium is difficult and needs more experience so molecular techniques are considered successful and more popular for Cryptosporidium diagnosis and also help in the species identification, in the herein study, PCR was nested proved to be more sensible and more specific to detect Cryptosporidium due to presence of a secondary round of amplifications Minarovičová et al. (2007), present sequence gave $100 \%$ identity with $C$. parvum and also clustered with $C$. parvum in the phylogenetic tree, so our morphological results were assured by the molecular analysis results which detected strongly positive samples with Cryptosporidium parvum, accompanied with the sequencing and the phylogenetic analysis.

Serum biochemical analysis manifested that liver enzyme activities including ALT and GGT were significantly elevated in diseased group in comparison with the control healthy group indicating pathological affection in liver or inflammation of gastrointestinal tract (Ghanem and Abd El-Raof, 2006), which agreed with Ghanem et al. (2012) and Youssef et al. (2017). GGT, a cell mem- brane attached enzyme in liver, kidney and small intestine, elevated with hepatocellular damage (Boonprong et al, 2007).

Lactate dehydrogenase (LDH) enzyme is a non-specific cytoplasmic enzyme found in different tissues of the body. LDH act as a catalyst converting lactate into pyruvate. Elevated serum level of LDH enzyme may refer to acute cell damage. Increased ALT, GGT \& LDH activities in the blood of cattle might be due to liver injury induced by acidosis (Mori et al, 2007).

The present study showed non-significant change in the levels of total proteins, albumin and globulin with significant decrement of IgA level in diseased group as compared with healthy one. Non-significant changes in the serum total protein level in all groups were in line with those results obtained by Youssef et al. (2017) and Ghanem et al. (2012). Normal values of total protein and albumin were even in liver injury unless hepatitis embraced a massive portion and intense enough to cause organ failure (Pincus and Schaffner, 1999). Fisher et al. (1975) and (Balikci and Al, 2014)found decreased serum IgA in diarrheic calves. Ghanem et al. (2012) deduced a non-significant change in $\alpha 1$ and $\alpha 2$ globulin but recorded significantly reduced serum levels of $\beta$-globulin and $\gamma$ globulin in the diarrheic buffalo calves compared to the control calves. $\gamma$-globulins have a remarkable role in humeral immunity that guard against pathogens. So, decrease in their level gives a sign of the suppressive effect of pathogens on the immune system.

The increased serum urea level and a nonsignificant change in creatinine level in diseased calves agreed with Osman and Sadiek (2008). Blood urea concentration depends on various factors as physiological state, nutrition, diarrhea and renal disease. Creatinine is a sharp index of renal insufficiency; therefore, there is no evidence of renal injury. The increased urea level might be due to decreased renal tubular flow rate, as a body trial to save fluids lost with diarrhea (Fisher, 1965). 
Liver is responsible for cholesterol synthesis and excretion. Hypercholesterolemia may result from decreased hepatic uptake or excretion into the bile. It is cleared from blood by forming steroids or removed by hepatocytes (Thrall et al, 2004). The present lipid profile results disagreed with those recorded by Bozukluhan et al. (2017). Fortuoso et al. (2018) reported lowered serum T.Gs levels and unchanged cholesterol levels in diarrheic calves. As formerly reported oocysts caused gut epithelial disruption; resulting in diarrhea (Chen et al, 2002). Mal nutrition may lead to decreased triglyceride level, as they are manufactured in the liver from dietary food or by being absorbed from the intestine (Ankur et al, 2012). Triglycerides are fats stored in the body due to ingested carbohydrates that were not instantly used (Smelt, 2010), so anorexia developed in diarrheic calves and mobilization of fat stores occurred with degradation of T.Gs into fatty acids \& glycerol. Akgün et al. (1998) found that many acute disease cases displayed decreased levels of plasma triglyceride.

In the present study, Halofuginone treated calves gave significant improvements in all analysis in comparison to diarrheic calves. So, Halofuginone lactate treated $C$. parvum infected calves. This agreed with Giadinis $e t$ al. (2008) who reported that Halofuginone lactate at a dosage of $100 \mu \mathrm{g} / \mathrm{kg}$ for 7 consecutive days was a potential treatment of cryptosporidiosis in goat kids and reduced diarrhea and fatality rate and minimized the environmental contamination.

\section{Conclusion}

Cryptosporidium parvum induced diarrhea in calves and a major problem of neonate calves. It caused significant change in hepatic biomarkers, lipid profile and IgA level of diseased calves. Halocur proved a promising treatment in dairy calves. ICT is a sensitive and rapid method for cryptosporidiosis detection with difficult morphological diagnosis. So, molecular techniques are the must.

Conflict of interest: Authors declared that they neither have competing interests, nor received any financial support.

\section{References}

Akgün, S, Ertel, NH, Mosenthal, A, Oser, W, 1998: Postsurgical reduction of serum lipoproteins: Interleukin-6 and the acute-phase response. J. Lab. Clin. Med. 13:103-8.

Allain, CC, Poon, LS, Chan, CS, Richmond, W, Fu, PC, 1974: Enzymatic determination of total serum cholesterol. Clin. Chem. 20:470-5.

Ankur, R, Nidhi, D, Seema, R, Amarjeet, D, Ashok, K, 2012: Hyperlipidemia-a deadly pathological condition. Int. J.Curr. Pharm. Res. 4:158.

Azami, M, 2007: Prevalence of cryptosporidium infection in cattle in Isfahan, Iran. J. Eukaryo. Microbiol. 54:100-2.

Bachorik, PS, 2000: Measurement of Low-Density-Lipoprotein Cholesterol. Handbook of Lipoprotein Testing, 2: 245-64.

Balikci, E, Al, M, 2014: Some serum acute phase proteins and immunoglobulins concentrations in calves with rotavirus, corona virus, $E$. coli F5 and Eimeria species. Iranian J. Vet. Res. 15:397-401.

Bartholomew, RJ, Delaney, AM, 1964: Spectrophotometric studies and analytical applications of the protein error of some $\mathrm{pH}$ indicators. Proc. Aust. Assoc. Clin.Biochem.1:64-8.

Bialeka, R, Bindera, N, Dietzb, K, Joachimc, A, Knobloch, J, et al, 2002: Comparison of fluorescence, antigen and PCR assays to detect $\mathrm{Cr}$ yptosporidium parvum in fecal specimens, Diagn. Microbiol. Infect. Dis. 43:283-8.

Boonprong, S, Sribhen, C, Choothesa, A, Parvizi, N, Vajrabukka, C, 2007: Blood biochemical profiles of thail indigenous and Simmental $x$ Brahman crossbred cattle in the central Thailand. J. Vet. Med. 54, 2:62-5.

Bozukluhan, K, Merhan, O, Gokce, HI, Deveci, HA, Gokce, G, et al, 2017: Alterations in lipid profile in neonatal calves affected by diarrhea. Vet. World 10:786-9.

Buhl, SN, Jackson, KY, 1978: Optimal conditions and comparison of lactate dehydrogenase catalysis of the lactate-to-pyruvate and pyruvateto-lactate reactions in human serum at $25,30, \&$ $37^{\circ} \mathrm{C}$. Clin.Chem. 24:828-31.

Chen, XM, Keithly, JS, Paya, CV, LaRusso, NF, 2002: Cryptosporidiosis. N. Engl. J. Med. 346, 22:1723-31.

Coles, EH, 1986: Veterinary Clinical Pathology. $4^{\text {th }}$ ed., WB Saunders Co., Philadelphia, London 
and Toronto.

Coulombe, JJ, Favreau, L, 1963: A new simple semimicro method for colorimetric determination of urea. Clin. Chem. 9:102-8.

Fayer, R, Morgan, U, Jupton, S, 2000: Epidemiology of Cryptosporidium: Transmission, detection and identification. Int. J. Parasitol. 30: 1305-22.

Fisher, EW, 1965: Death in neonatal calf diarrhea. Br. Vet. J. 121:132-8.

Fisher, EW, Martinez, AA, Trainin, Z,Meirom, R, 1975: Studies of neonatal calf diarrhoea. II. Serum and fecal immune globulins inentericcolibacillosis. Br. Vet. J. 131:402-15.

Fortuoso, BF, Volpato, A, Rampazzo, L, Glombowsky, P, Griss, LG, et al, 2018: Homeopathic treatment as an alternative prophylactic to minimize bacterial infection and prevent neonatal diarrhea in calves. Microbial Pathogenesis, 114:95-8.

Fossati, P,Prencipe, L, 1982: Serum triglycerides determined colorimetrically with an enzyme that produces hydrogen peroxide. Clin. Chem. 28, 10:2077-80.

Georgi, JR, Georgi, ME, 1990: Parasitology for Veterinarians. $5^{\text {th }}$ ed.,WB Saunders Co., Philadelphia, USA.

Ghanem, MM, Abd El-Raof, YM, 2006: Clinical and haematobiochemical studies on lamb coccidiosis and changes following Amprolium and sulphadimethoxine therapy. Benha Vet. Med. J. 16:59-63.

Ghanem, MM, El-Fkhrany, SF, Abd El-Raof, Y, El-Attar, H, 2012: Clinical and haemato-biochemical evaluation of diarrheic neonatal buffalo calves (Bubalasbubals) with reference to antioxidant changes. Benha Vet. Med. J. 23:275-88. Ghoneim, NH, Hassanain, MA, Hamza, DA, Shaapan, RM, Draz, SH, 2017: Prevalence and molecular epidemiology of Cryptosporidium infection in calves and hospitalized Children in Egypt. Res. J. Parasitol. 12:19-26.

Giadinis, ND, Papadopoulos, SQ, Lafic, NK, Panousis, M, Karatzias, H, 2008: Efficacy of halofuginone lactate for the treatment and prevention of cryptosporidiosis in goat kids: An extensive field trial. Small Rumi. Res. 76:195-200.

Gornall, AG, Bardawill, CJ, David, MM, 1949: Determination of serum proteins by means of biuret reaction. J. Biol. Chem. 177:751-66.

Göz, Y, Altu, N, Yüksek, N, Özkan, C, 2006: Parasites detected in neonatal and young calves with diarrhea. Bull. Vet. Inst. Pulawy, 50:345-8. Harp, JA, Jardon, P, Atwill, ER, Zylstra, M,
Checel, S, et al, 1996: Field testing of prophylactic measures against Cryptosporidium parvum infection in calves in a California dairy herd. Am. J.Vet. Res. 57:1586-8.

Henriksen, SA, Pohlenz, JF, 1981: Staining of cryptosporidia by a modified Ziehl-Neelsen technique. Acta Vet. Scand. 22:594-6.

Henry, RJ, 1974: Clinical Chemistry Principle and Techniques, $2^{\text {nd }}$ ed. Harper and Row.

Abdel Megeed, KN, Hammam, AM, Morsy, GH, Khalil FAM, Seliem, MME, et al, 2015: Control of Cryptosporidiosis in Buffalo Calves Using Garlic (Allium sativum) and Nitazoxanide with Special Reference to Some Biochemical Parameters. Glo. Vet. 14, 5:646-55.

Kaneko, JJ, John, WH and Michael, LLB, 1997: Clinical Biochemistry of Domestic Animals. $4^{\text {th }}$ ed., Academic Press, NewYork.

Lefay, D, Naciri, M, Poirier, P, Chermette, R, 2001: Efficacy of halofuginone lactate in the prevention of cryptosporidiosis in suckling calves. Vet. Rec. 148:108-12.

Levesque, A, 2007: Programming and Data Management: A Guide for SPSS and SAS Users, $4^{\text {th }}$ Edition, SPSS Inc., Chicago III.

Minarovicova, J, Kaclikova, E, Krascsenicsova, K, Peter, S, 2007: Detection of Cryptosporidiumparvum by polymerase chain reaction, $\mathrm{J}$. Food Nutr. Res. 46:58-62.

Mori, A, Urabe, S, Asada, M, Tanaka, Y, Tazaki, H, et al, 2007: Comparison of plasma metabolite concentrations and enzyme activites in beef cattle raised by different feeding systems in Korea, Japan and New Zeland. J. Vet. Med. Physiol. Pathol. Clin. Med. 54, 7:342-5.

Osman, FA, Sadiek, AH, 2008: Role of Cryptosporidial infection as a pathogen of neonatal calf diarrhea in Assiut Governorate. $13^{\text {th }}$ Cong. Fac. Vet. Med., Assiut University.

Pincus, MR, Schaffner, JA, 1999: Liver function. In: Clinical Diagnosis and Management by Laboratory Methods. Henry JB. $19^{\text {th }}$ ed., São Paulo, Manhole.

Radostits, OM, Gay, CC, Hinchcliff, KW, Houston, DM, 2000: Veterinary Clinical Examination and Diagnosis, London, Philadelphia, N/ Y. Radostits, OM, Gay, CC, Hinchcliff, KW, Constable, PD, 2007: Veterinary Medicine. In: A Textbook of Diseases of Cattle, Horses, Sheep, Pigs and Goats. $10^{\text {th }}$ ed. London, Philadelphia, New York.

Reitman, S, Frankel, S, 1957: A colorimetric method for the determination of serum glutamic 
oxalacetic and glutamic pyruvic transaminases. Amer. J. Clin. Pathol. 28:56-63.

Smelt, AH, 2010: Triglycerides and gallstone formation. Clin. Chim. Acta.411:1625-31.

Szasz, G, 1969: A kinetic photometric method for serum gamma-glutamyl transpeptidase. Clin. Chem. 15:124-36.

Thrall, MA, Baker, DC, Campbell, TW, De Nicola, D, Fettman, M, et al, 2004. Veterinary Hematology and Clinical Chemistry: Text \& Clinical Case Presentations, Lippincott Williams and Wilkins, USA.

Tiez, NW, 1990: Clinical Guide to Laboratory Tests. $2^{\text {nd }}$ ed. Philadelphia, USA. W.B. Saunders
Co.

Vanathy, K, Subhash, CP, Jharna, M, AbdoulHamide, A, Sriram, K, 2017: Detection of Cryptosporidium in stool samples of immunocompromised patients. Trop. Parasitol. 7, 1:41-6. Yagita, K, Izumiyama, S, Tachibana, H, Masuda, G, Isekli, M, et al, 2001: Molecular characterization of Cryptosporidium isolates obtained from human and bovine infection in japan. Parasitol. Res. 87:95-9.

Youssef, MA, El-Ashker, MR, Ouda, MF, 2017: Hematological and serum biochemical alterations in buffalo with some digestive disorders. Compar. Clin. Pathol. 26:1033-9.

\section{Explanation of figures}

Fig. 1: Cryptosporidium oocysts stained with Modified Ziehl-Neelsen stain.

Fig. 2: Electrophoretic separation of $18 S r R N A$ gene. L1: ladder (100bp); lane L2, L3, L6, L7: positive samples; L4: negative control, L5: positive control.

Fig. 3: Phylogenetic analysis constructed using UPGMA methods, to construct phylogenetic tree of Cryptosporidium species sequences from Genbank and sequence sample (AHNE1).
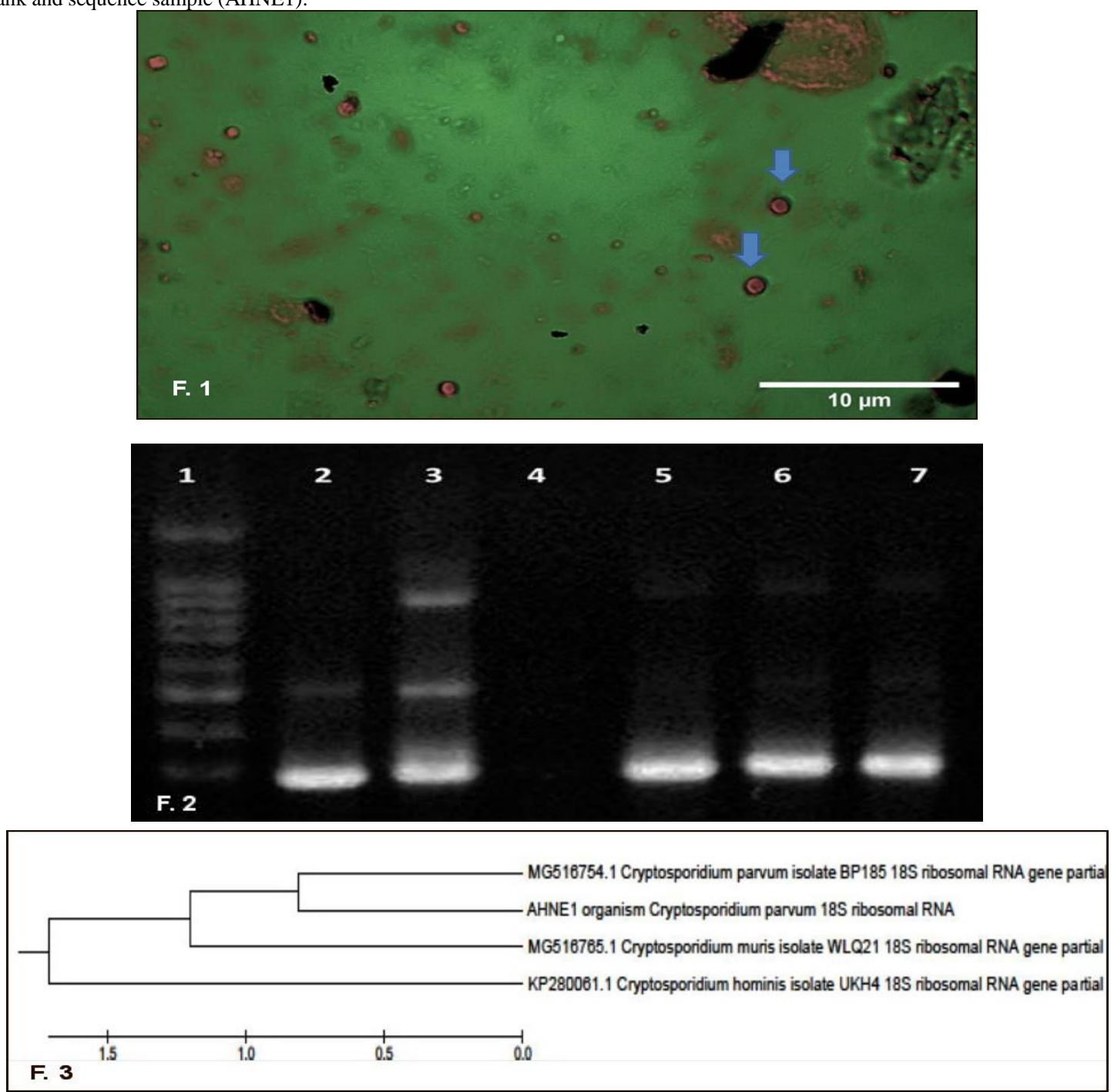